\title{
Ginandroblastoma multiloculado, negativo para CD99 en una niña de 12 años. Caso clínico
}

\author{
A twelve-years-old girl with multiloculated gynandroblastoma CD99 \\ negative. Case report
}

\section{Estud. Med. Jairo Alonso Sierra-Avendaño ${ }^{a}$, Dr. Ricardo García-Pino ${ }^{a}$ y Dr. Gabriel Eduardo Pérez-García ${ }^{a}$}

\begin{abstract}
RESUMEN
Losginandroblastomas son tumores del ovarioextremadamente raros, los cuales comparten componentes de células de la granulosa y de células de Sertoli/Leydig. Se describe un caso de una niña de 12 años, quien presenta hemorragia uterina anormal y sensación de masa intraabdominal de crecimiento progresivo asociado a menorragia, niveles de CA-125 en 60,4 $\mathrm{UI} / \mathrm{mL}$ y estudios de extensión que reportan masa quística en ovario izquierdo, manejada con ooforectomía. El estudio anatomopatológico muestra un tumor multiloculado lleno de material seroso, abundantes cuerpos de Call-Exner y $45 \%$ de células de Sertoli/Leydig. La inmunohistoquímica reveló inmunorreactividad para inhibina, calretinina y $\mathrm{pCK}$, mientras que los marcadores CD99 y AE1/AE3 fueron negativos. Se trata del primer reporte de caso sobre un ginandroblastoma multiloculado, negativo para CD99 en una niña de 12 años, estudio que plantea un abordaje sistemático para los tumores de las células de los cordones sexuales.

Palabras clave: tumores del estroma y los cordones sexuales, ginandroblastoma, niños, inmunohistoquímica, antígeno humano CD99.
\end{abstract}

\begin{abstract}
The ginandroblastoma is an extremely rare ovarian tumor which shows components of granulosa cells and Sertoli/Leydig cells. We describe a case of a twelve-years-old girl who presented abnormal uterine bleeding and progressively growing intraabdominal mass associated with menorrhagia, CA-125 60.4 $\mathrm{UI} / \mathrm{mL}$ and extension studies reporting cystic mass in the left ovary. She underwent oophorectomy. Pathological study shows a multilocular tumor filled with serous material. Many Call-Exner bodies were observed in the histopathological analysis, $45 \%$ of Sertoli/Leydig cells. Immunohistochemistry was reactive for inhibin, calretinin and pCK while AE1/AE3 and CD99 markers were negative. This is the first case report about a multiloculated gynandroblastoma, negative for CD99 in a12-years-old girl. Thus, the study of this clinical case represents a systematic approach for tumors of the sex cord cells.

Key words: sex cord-gonadal stromal tumors, gynandroblastoma, children, immunohistochemistry, human CD99 antigen.
\end{abstract}

a. Grupo de Patología Estructural, Funcional y Clínica de la Universidad Industrial de Santander (PAT-UIS), Departamento de Patología, Escuela de Medicina, Universidad Industrial de Santander. Bucaramanga, Colombia.

Correspondencia:

Dr. Gabriel E. Pérez-García: juancamapa@yahoo.com.ar

Conflicto de intereses: ninguno que declarar.

Recibido: 18-11-2013

Aceptado: 13-1-2014 http:/ / dx.doi.org/10.5546/aap.2014.e142

\section{INTRODUCCIÓN}

Los ginandroblastomas son raras neoplasias de células de los cordones sexuales, cuya tumorogénesis aún no está clara. El término ginandroblastoma fue usado por primera vez en 1927, cuando Robert Meyer ${ }^{1}$ describió una serie de casos de "arrenoblastomas" que presentaban características propias de tumores de la granulosa acompañados de hipertrofia uterina. Desde entonces, múltiples casos aislados han sido reportados, principalmente en pacientes adultos, ${ }^{2}$ ya que es rara su presentación en niños.

La OMS establece cuatro grupos en la clasificación histológica de las neoplasias del ovario, derivadas del estroma y los cordones sexuales: ${ }^{3}$

1. Tumores de células de los cordones sexuales.

2. Tumores de las células de Sertoli.

3. Tumores que contienen células de los cordones sexuales o tipos celulares no clasificados.

4. Tumores de células esteroideas.

Los dos últimos hacen referencia a grupos de tumores con bajas incidencias. El ginandroblastoma está incluido en el tercero de estos.

La inmunohistoquímica es una herramienta necesaria para abordar estas neoplasias al emplear marcadores específicos. La inhibina se describe como un marcador muy útil, ${ }^{4,5}$ pero posee una especificidad baja entre los casos de neoplasias de los cordones sexuales, por lo cual se han sumado otros, como CD99, citoqueratinas $\mathrm{y}$, más recientemente, calretinina. ${ }^{6,7}$ Son pocos los estudios que han evaluado la utilidad diagnóstica de este panel completo, en el cual se incluyen otros antígenos, como la panqueratina (pCK) y el antígeno epitelial de membrana (EMA), ${ }^{6}$ de tal manera que conformen un esquema que permita diferenciar el componente de células de Sertoli del componente de células de la granulosa dependiendo de su intensidad.

En este trabajo, el cual empleó la inmunohistoquímica como complemento del estudio histopatológico, reportamos un caso de 
ginandroblastoma con características únicas al presentarse como una masa multiloculada en una niña de 12 años, negativo para el marcador CD99.

\section{CASO CLÍNICO}

Paciente de 12 años de edad cuya menarquia ocurrió hace un año. Consulta al Servicio de Urgencias por presentar desde hace 7 meses sangrado vaginal, que se hizo permanente durante los últimos cuatro meses, y sensación de masa abdominal con aumento progresivo de tamaño. La ecografía realizada reportó la presencia de una masa quística compleja dependiente de anexo izquierdo; sus paredes miden 2,2 mm, con diámetros de $11,7 \times 4,0 \mathrm{~cm}$. Se realizó una tomografía abdominal, que mostró una masa quística de naturaleza inespecífica. El Servicio de Radiología contempló, como posibilidades diagnósticas, quiste de ovario, quiste mesentérico y malformación linfática.

Los marcadores séricos alfafetoproteína, antígeno carcinoembrionario y $\beta$-hCG se encontraban en sus rangos normales; el CA-125 reportado fue de 60,4 UI/mL. Seguidamente, el Servicio de Ginecooncología planteó la necesidad de realizar una laparotomía exploratoria.

Tras la intervención quirúrgica, se describe un tumor de tipo inespecífico y comportamiento incierto ubicado en el ovario izquierdo.

Para el estudio histopatológico, se obtuvo en fresco el ovario izquierdo, cuyo peso fue de 298 gramos, sus medidas fueron $14,8 \times 14,0 \times 3,5 \mathrm{~cm}$ en sus diámetros mayores cruzados (Figura 1a). $\mathrm{Al}$ corte, estaba totalmente reemplazado por una lesión sólido-quística multiloculada de contenido seroso, sin formación de papilas. El estudio microscópico reveló una lesión tumoral originada en los cordones sexuales, conformada por células

FIGURA 1. Estudio histopatológico convencional. a. Vista macroscópica de una masa ovárica quística y multiloculada (flechas). b. Componente de células de la granulosa con abundantes cuerpos de Call-Exner (flechas), entremezclados con el componente de células de Sertoli en un 45\%. c. Componente de células de Sertoli (flecha roja) con áreas sólidas de células de la granulosa y cuerpos de Call-Exner en la parte inferior (flechas negras). d. Formación de túbulos anulares vistos en cortes microscópicos transversales (flechas negras) longitudinales (flecha roja).
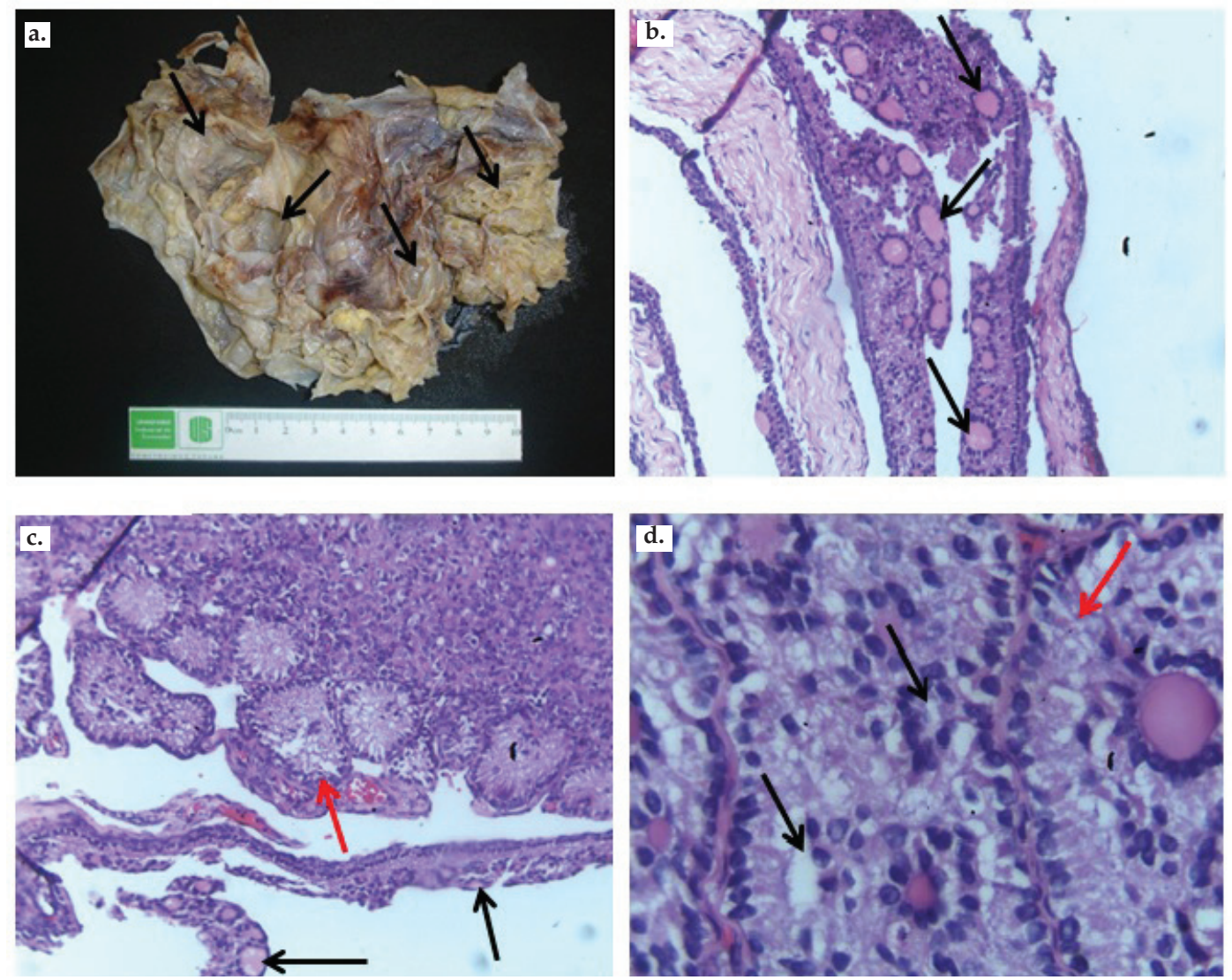
de tamaño pequeño, con núcleos hipercromáticos, indentaciones nucleares, nucléolo prominente y citoplasma escaso, las cuales se disponen en un patrón macro- y microfolicular, con formación de cuerpos de Call-Exner (Figura 1b). Se identificó una segunda población de células neoplásicas, con apariencia entre cúbica y cilíndrica, de núcleos pequeños, monomorfos, citoplasma claro levemente eosinófilo debido a la formación de vacuolas acompañadas por estructuras tubulares (Figura 1c y 1d).

La inmunohistoquímica mostró una fuerte reactividad para calretinina e inhibina, con marcación moderada para el antígeno Ae1/Ae3. No hubo inmunorreactividad para el EMA ni para CD99 (Figura 2). Se evidenció positividad de la calretinina y la inhibina en el material proteináceo que se encontraba en los quistes. Con estos hallazgos, se corroboró el diagnóstico de ginandroblastoma.

\section{DISCUSIÓN}

Este tipo de tumores ováricos constituyen una rara causa de producción excesiva de andrógenos, por consiguiente, las pacientes pueden manifestar signos de virilización. ${ }^{8}$ Estos son datos clínicos importantes para orientar la sospecha diagnóstica de una masa ovárica asociada con producción elevada de hormonas sexuales, tanto estrógenos como andrógenos. La paciente carecía de estas manifestaciones.

Los ginandroblastomas presentan células de Leydig y/o de Sertoli con componentes de la granulosa. ${ }^{1}$ Estos se consideran tumores de muy bajo potencial de malignidad, ${ }^{2}$ aunque con posibilidad de presentar recurrencias. No se ha descrito la ocurrencia de enfermedad metastásica. Sobre el conjunto de tumores de células de la granulosa o los tumores de Sertoli y Leydig, se ha descrito enfermedad con verdadero potencial maligno, metástasis y muerte, ${ }^{9}$ pero no es el caso de los ginandroblastomas. Sin embargo, uno de los factores que debe evaluarse durante el examen de las pacientes es la hiperplasia endometrial, debido a la posible malignización, pero dicha condición, por lo general, se revierte de modo espontáneo luego de la resección. ${ }^{8}$

La edad de presentación varía entre los 15 y los 69 años, pero esta paciente resulta ser la más joven dentro de todos los casos reportados, incluidos los de McCluggage y Yamada. ${ }^{10,11}$

Al no haber un consenso preciso para el abordaje diagnóstico del ginandroblastoma, se ha adoptado la aproximación que hace la OMS, usando básicamente alfainhibina, marcador positivo en muchas neoplasias de los cordones sexuales; sin embargo, no se hace referencia a otros inmunomarcadores. ${ }^{3}$ Roth y MatiasGuiu $^{5,12}$ han trabajado en la clarificación de este panorama tomando marcadores, como la inhibina y CD99, junto con la revisión histológica de los especímenes quirúrgicos. A mediados de la década pasada, Cathro y Stoler, ${ }^{7}$ observando los resultados de un anticuerpo para las proteínas fijadoras de calcio expresadas primariamente en tumores de células de la granulosa, introdujeron la calretinina en el panel de abordaje diferencial de estas neoplasias. McCluggage y Baker han incluido el CD99 para estudiar los tumores de células de granulosa de tipo juvenil, ${ }^{11,13}$ a pesar de que actualmente su significancia diagnóstica no es clara.

Quizá el estudio realizado por Zhao y colaboradores ${ }^{14}$ sea el más concluyente al afirmar que los marcadores que proveen más información en los casos de tumores de los cordones y el estroma sexual, distinguiéndolos de otros tipos de tumores, son inhibina, calretinina, SF-1 y WT-1 (estos dos últimos no están disponibles en nuestro medio).

Macroscópicamente, los ginandroblastomas son neoplasias sólido-quísticas y unilaterales; el componente sólido es de aspecto nodular y el componente quístico, de contenido seroso. Hay también reportes de tumores completamente sólidos y otros que, a diferencia del aquí presentado, se conforman por un quiste único no loculado. ${ }^{15}$ Histológicamente, la característica más importante es la presencia de células propias de la granulosa junto con las hendiduras nucleares, rasgo que constituye la imagen clásica de "granos de café". Estas se reúnen alrededor de un glóbulo hialino, conformando los cuerpos de Call-Exner, que se asemejan a los folículos primarios que se entremezclan difusamente con túbulos bien diferenciados, tapizados por células de Sertoli. Pueden existir variaciones a este patrón, pero, sin importar la variedad del tumor, el menor de los dos componentes debe estar en, por lo menos, un $10 \%$ de la examinación para considerarse un ginandroblastoma, ${ }^{3}$ hallazgo fácilmente reconocible por el patólogo.

En ese orden de ideas, los marcadores más apropiados son aquellos que suelen compartir los componentes de los tumores de la granulosa y los de células de Sertoli/Leydig. Los que muestran un grado variable de inmunorreactividad son la vimentina, el CD99 y las citoqueratinas. Para 
FIGURA 2. Estudio inmunohistoquímico del tumor de ovario. Las imágenes muestran el perfil de marcadores de inmunohistoquímica que presentó el tumor. Calretinina $(a, b)$ e inhibina $(c)$ presentan una fuerte reactividad en el componente celular. El marcador AE1/AE3 (e) revela positividad focal en el componente tumoral de los túbulos, mientras que CD99 (d) y EMA (f) resultan ser negativos.

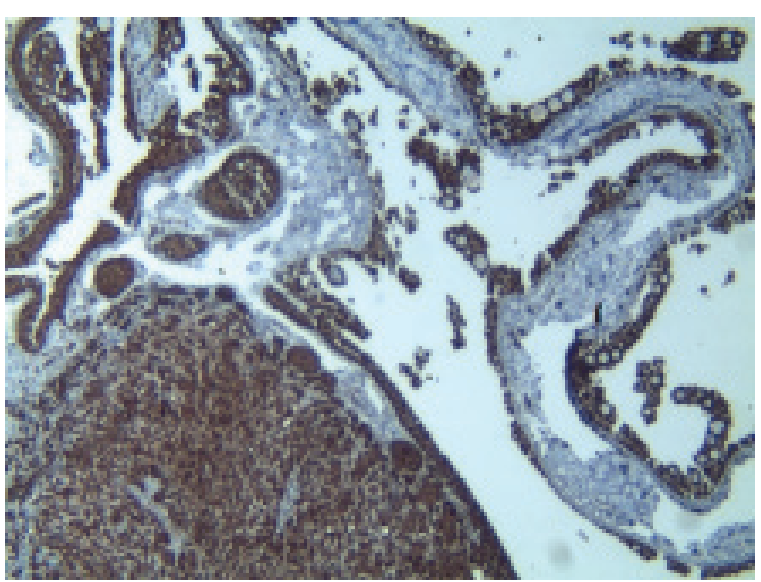

a. Calretinina

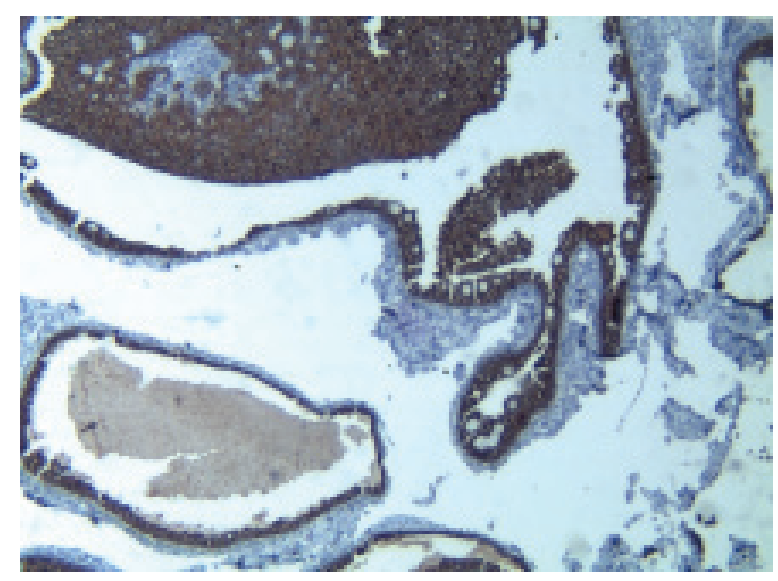

c. Inhibina

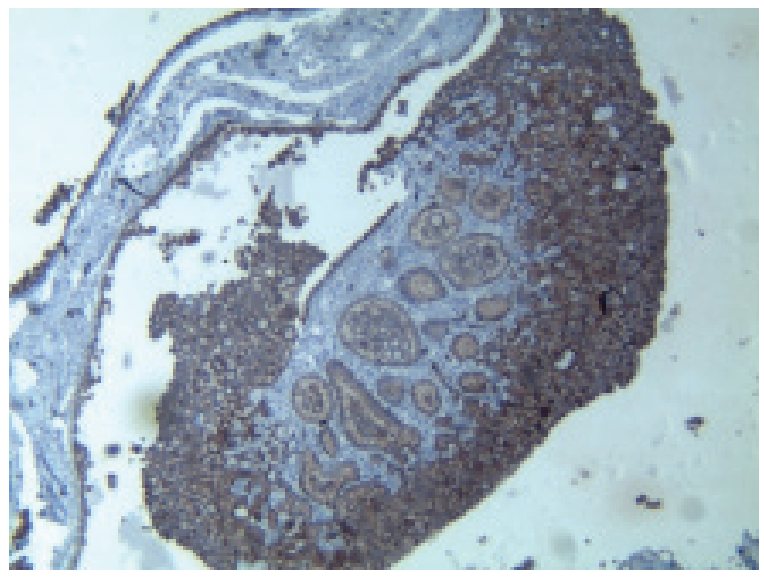

e. pCK

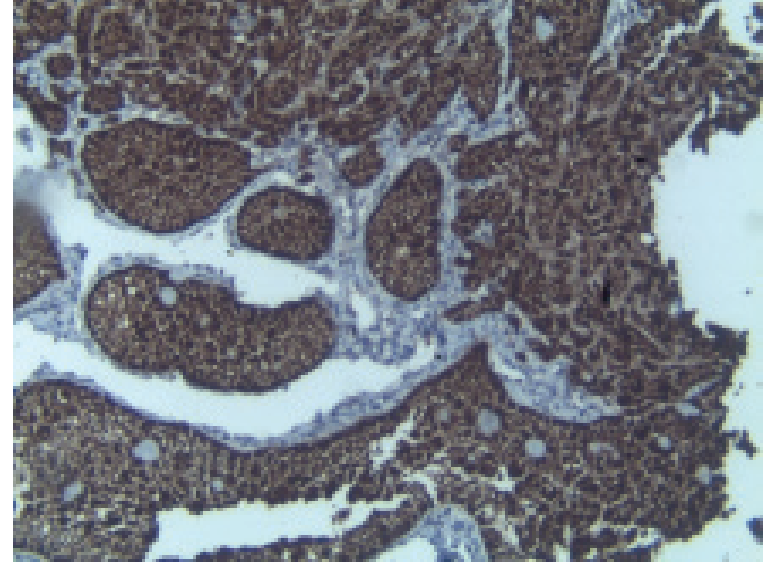

b. Calretinina

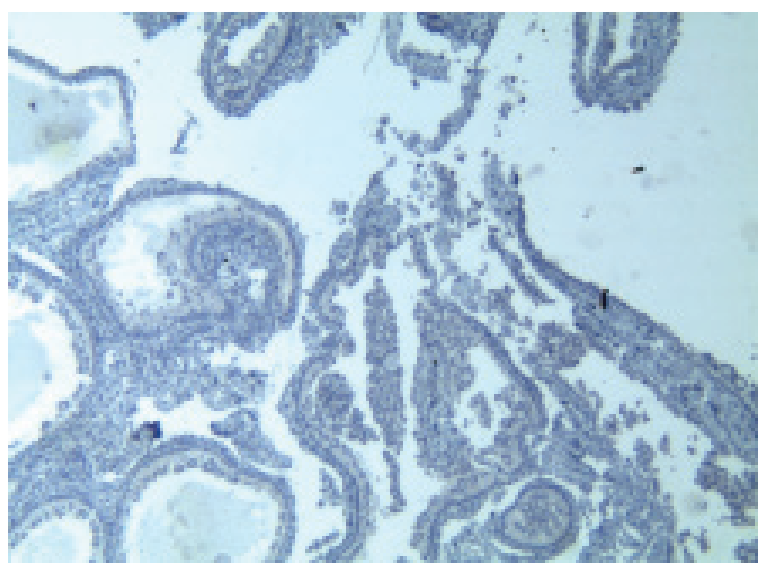

d. CD 99

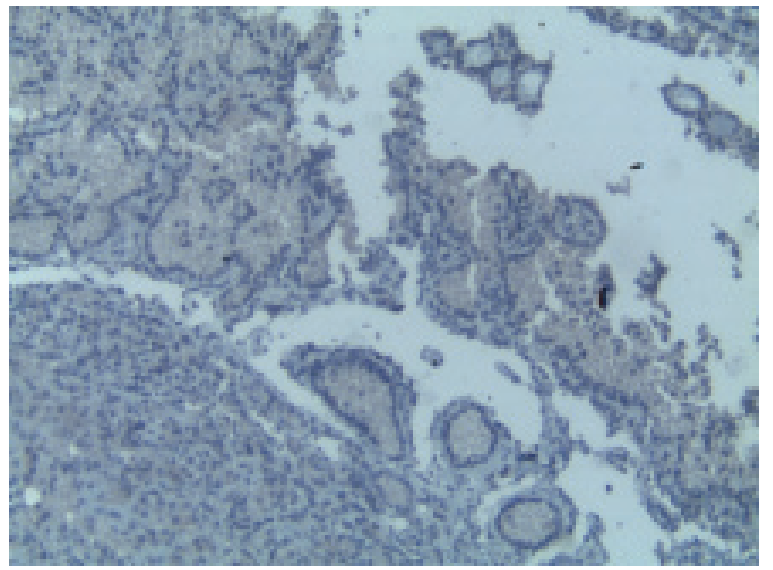

f. EMA 
el caso de CD99, se plantea que, a pesar de ser una molécula de adhesión ubicuamente expresada, cobra importancia al momento de evaluar su afinidad como una glucoproteína tipo sialomucina. ${ }^{7}$ El marcador se usa en casos de sarcoma de Ewing, tumor neuroectodérmico primitivo, linfoma/leucemia linfoblástico, algunos rabdomiosarcomas, tumores de la granulosa y de células de Sertoli en el ovario, tumores pancreáticos endocrinos y carcinomas de vesícula y estómago. ${ }^{7}$ Este es un marcador que permitiría evaluar posibles metástasis o la presencia de los llamados tumores de "células pequeñas, redondas y azules", muy prevalentes en niños.

El trabajo presentado varía de los anteriores reportes, en primer lugar, por la edad de la paciente y por la apariencia macroscópica del tumor, al ser quístico multiloculado, sin formaciones papilares. En segundo lugar, llama la atención que el CD99 es negativo, rasgo no enunciado en otros reportes de casos en los que se ha usado. Aunque es difícil recopilar una amplia casuística que permita determinar con certeza la inmunofenotipificación de estos tumores, se espera que, en un futuro, un gran estudio contribuya a lo que puede ser la aproximación biológica y posterior terapéutica de los diversos tumores ováricos.

\section{BIBLIOGRAFÍA}

1. Mechler EA, Black WC. Gynandroblastoma of the ovary. Am J Pathol 1943;19(4):633-53.

2. Chivukula M, Hunt J, Carter G, Kelley J, et al. Recurrent gynandroblastoma of ovary. A case report: a molecular and immunohistochemical analysis. Int J Gynecol Pathol 2007;26(1):30-3.
3. Tavassoli FA, Devilee P, eds. Pathology and genetics of tumours of breast and female genital Organs. Lyon: IARC Press; 2003.

4. Choi YL, Kim HS, Ahn G. Immunoexpression of inhibin alpha subunit, inhibin/activin betaA subunit and CD99 in ovarian tumors. Arch Pathol Lab Med 2000;124(4):563-9.

5. Roth LM. Recent advances in the pathology and classification of ovarian sex cord-stromal tumors. Int J Gynecol Pathol 2006;25(3):199-215.

6. McCluggage WG, Young RH. Immunohistochemistry as a diagnostic aid in the evaluation of ovarian tumors. Semin Diagn Pathol 2005;22(1):3-32.

7. Cathro HP, Stoler MH. The utility of calretinin, inhibin, and WT1 immunohistochemical staining in the differential diagnosis of ovarian tumors. Hum Pathol 2005;36(2):195201.

8. Ray-Coquard I. Ovarian malignant tumors of sex cordstromal origin. Orphanet Encyclopedia 2004. [Consulta: 26 de sept 2013]. Disponible en: http:/ / www.orpha.net/ consor/cgi-bin/OC_Exp.php?lng=EN\&Expert=35808.

9. WidschwendterM,MeduriG,Loosfelt $\mathrm{H}$,SchrocksnadelH, et al. Fulminant recurrence of a Sertoli-Leydig cell tumour during pregnancy. Br J Obstet Gynaecol 1999;106(3):284-5.

10. Limaiem F, Lahmar A, Ben Fadhel C, Bouraoui S, M'zabiRegayaS. Gynandroblastoma. Report of an unusual ovarian tumour and literature review. Pathologica 2008;100(1):13-7.

11. McCluggage WG, Sloan JM, Murnaghan M, White R. Gynandroblastoma of ovary with juvenile granulosa cell component and heterologous intestinal type glands. Histopathology 1996;29(3):253-7.

12. Matias-Guiu X, Pons C, Prat J. Müllerian inhibiting substance, alpha-inhibin, and CD99 expression in sex cordstromal tumors and endometrioid ovarian carcinomas resembling sex cord-stromal tumors. Hum Pathol 1998;29(8):840-5.

13. Baker RJ, Hildebrandt RH, Rouse RV, Hendrickson MR, Longacre TA. Inhibin and CD99 (MIC2) expression in uterine stromal neoplasms with sex-cord-like elements. Hum Pathol 1999;30(6):671-9.

14. ZhaoC, Vinh TN,McManus K, Dabbs D, et al. Identification of the most sensitive and robust immunohistochemical markers in different categories of ovarian sex cord-stromal tumors. Am J Surg Pathol 2009;33(3):354-66.

15. Talmon GA, Persidskii I, GuliziaJA. A cystic mass in a young woman with presumed polycystic ovarian syndrome. Gynandroblastoma. Arch Pathol Lab Med 2006;130(2):225-6. 